\title{
PERANCANGAN JARINGAN KOMPUTER DISKLESS BERBASIS LINUX TERMINAL SERVER PROJECT PADA SISTEM OPERASI UBUNTU 8.04
}

\section{DISKLESS COMPUTER NETWORK DESIGN BASED LINUX TERMINAL SERVER PROJECT ON UBUNTU 8:04 OPERATING SYSTEM}

\author{
Harry Rakhmat $\mathrm{H}^{1}$, Yudha Purwanto, ST., MT. ${ }^{2}$, Indrarini Dyah I, ST., MT. ${ }^{3}$ \\ ${ }^{1,2.3}$ Fakultas Elektro dan Komunikasi IT Telkom Bandung \\ 1'harry_iwing@yahoo.com, ${ }^{2}$ ydp@ittelkom.ac.id, ${ }^{3}$ indrarini@ $@$ telkomuniversity.ac.id
}

\begin{abstract}
Abstrak
Linux Terminal Server Project (LTSP) merupakan sebuah proyek jaringan computer diskless berbasiskan sistem operasi GNU/linux yang dimulai oleh James A McQuillan. Komputer diskless adalah perangkat client atau workstation yang tidak dilengkapi dengan media penyimpanan tetap. Teknologi ini makin populer karena dapat menghemat sumber daya hardware. Dalam penelitian ini dirancang jaringan computer dengan menggunakan Personal Computer (PC) sekelas pentium D sebagai workstation, tanpa dilengkapi media penyimpanan dan PC sekelas pentium core 2 duo sebagai server. LTSP akan diintegrasikan pada sistem operasi linux ubuntu 8.04. Kemudian dilakukan pengujian performasi terhadap CPU server dan penggunaan memori server ketika client menggunakan aplikasi Openoffice, Gimp dan Firefox. Hasil penelitian menunjukkan bahwa server mampu melayani 8 client secara bersamaan. CPU usage dengan menjalankan tiga aplikasi tersebut masih dalam keseimbangan, yaitu berkisar antara 65-70\% untuk user time, 30-35\% untuk system time dan 0-0,5\% idle time. Penggalokasian swap muncul ketika nilai "free" berkisar antara 14.000 Kbyte-30.000 Kbyte.
\end{abstract}

Kata kunci: LTSP, Server, Diskless, Ubuntu

\begin{abstract}
Linux Terminal Server Project (LTSP) is a diskless computer network project based operating system GNU / Linux that was started by James A McQuillan. Diskless computer is the client or workstation not equipped with a permanent storage medium. This technology is increasingly popular because it can save on hardware resources. In this research, designing computer network used a PC (Personal Computer) Pentium D class as the workstation, regardless of storage media and PCs equipped with Pentium-class core 2 duo as a server. LTSP would be integrated with 8.04 ubuntu linux operating system. Then testing performance of CPU usage and memory usage of the server when the client application uses Openoffice, Gimp and Firefox. The results showed that the server is capable of serving 8 clients simultaneously. CPU usage by running three applications are still in the balance, which ranges between $65-70 \%$ for user time, 30-35 \% for the system time and 0-0.5 \% idle time. Swap arises when the value of "free" ranging between 14.000- 30.000 Kbyte.
\end{abstract}

Keywords: LTSP, Server, diskless, Ubuntu 


\section{PENDAHULUAN}

Dewasa ini teknologi komputer baik dalam perangkat lunak maupun perangkat keras mengalami perkembangan yang begitu cepat. Tentu saja hal ini berdampak positif bagi kehidupan manusia. Berbagai aplikasi mulai dikembangkan dengan memanfaatkan teknologi komputer untuk memudahkan manusia melakukan aktifitasnya. LTSP merupakan sebuah proyek untuk membuat terminal server di Linux. Dengan aplikasi LTSP tersebut maka klien diskless dapat mengakses server Linux dan menjalankan berbagai aplikasi yang berjalan di atasnya. Kabar baiknya adalah administrator dapat memanfaatkan PC lama sebagai client nya. Komputer sekelas 486 dan Pentium I dengan RAM 16 MB keatas, tanpa harddisk, dapat digunakan untuk menjalankan distro linux terbaru lengkap dengan berbagai aplikasinya. Bayangkan berapa dana hardware yang dapat dihemat dengan teknik ini. Administrator juga tidak perlu membeli lisensi OS dan aplikasinya karena Linux, LTSP, dan berbagai aplikasinya dapat diperoleh tanpa membayar lisensi. Administrator jaringan tidak perlu menginstal linux dan aplikasinya satu per satu di tiap client. Aplikasi cukup dipasang di server saja, dan client menjalankan aplikasi tersebut. Semua processing terjadi di server, sehingga kecepatan proses akan mengikuti spesifikasi server. Manfaat lainnya adalah troubleshooting dan backup data menjadi lebih mudah, karena aplikasi dan data terpusat di server.

Jaringan komputer diskless berbasis LTSP diimplementasikan menggunakan sebuah server yang terhubung dengan 4-8 client dengan media transmisi kabel UTP cat 5e. Konsentrator switch/hub dan NIC 10/100Mbps digunakan untuk menghubungkan PC yang ada pada sistem jaringan komputer diskless. Sistem operasi yang digunakan adalah ubuntu 8.04. Aplikasi yang dijalankan dalam sistem jaringan komputer diskless untuk melakukan pengujian adalah OpenOffice, Gimp dan Firefox. Kemuadian diukur performasi CPU Server serta penggunaan memori dalam jaringan komputer diskless.

\section{TEORI}

\subsection{Jaringan Komputer Diskless}

Jaringan komputer diskless adalah suatu jaringan komputer atau mesin yang dapat beroperasi tanpa adanya dukungan media penyimpanan (storage atau disk) lokal. Ini tidak berarti bahwa mesin tidak mempunyai disk sama sekali. Semua data disimpan terpusat pada satu server jaringan komputer diskless. Jaringan komputer diskless memulai operasi dengan memanggil sistem file dari server jaringan diskless, bukan dari storage lokal seperti yang biasa digunakan. Proses diskless akan membantu komputer client untuk dapat mengaktifkan sistem operasi tersebut dengan mengekseskusi file kernel di sisi komputer client. Setelah proses diskless selesai, dilanjutkan dengan akses melalui jaringan untuk mengeksekusi X-Server di sisi komputer client, sehingga komputer client dapat mengakses aplikasi diskless. Proses tersebut memungkinkan komputer lama seperti komputer 486 yang mempunyai RAM 8 MB menggunakan diskless dapat menjalankan kernel dan mengeksekusi X-Server. Setelah proses eksekusi berhasil, maka proses dialihkan ke XDM pada komputer client dengan konfigurasi yang tinggi. Proses yang telah diarahkan tersebut seolah-olah berjalan di komputer client dengan kecepatan yang tinggi. Sebenarnya, proses tersebut terjadi di server sedangkan outputnya diclient. Booting melalui jaringan merupakan konsep lama, ide dasarnya adalah komputer client dengan kode booting seperti BOOTP (boot protocol) atau DHCP (Dynamic Host Configuration Protocol) dalam memory non-volatile (ROM) chips mendapatkan sistem file root server dalam suatu jaringan ketika komputer client tidak dilengkapi dengan media penyimpanan, misalnya harddisk. 


\subsection{Linux Terminal Server Project}

LTSP (Linux Terminal Server Project) adalah aplikasi untuk membangun jaringan thinclient atau diskless. Client-server LTSP disebut thin client karena komputer client hanya digunakan untuk menjalankan sistem operasi minimal, sedangkan semua program aplikasi dijalankan di server. Jaringan LTSP juga disebut diskless, karena komputer client tidak bekerja dengan harddisk sendiri. LTSP pada intinya adalah satu set script yang memungkinkan kita menampilkan layar server di client, Tentu saja di dalamnya jauh lebih kompleks, ada fasilitas remote boot, remote file system, hardware auto detection, remote multimedia \& output, dan lain-lain. LTSP menyediakan suatu cara untuk menggunakan komputer kerja murah baik sebagai terminal yang berbasis grafis maupun yang berbasis teks pada server GNU/Linux [2,3,5,6,7]. Dengan menggunakan LTSP, penggunaan low end PC (tanpa menggunakan harddisk, floppy disk, maupun CD ROM) dapat ditingkatkan. Pada low end $P C$ cukup ditambahkan lan card yang dapat diboot [4].

\section{PERANCANGAN DAN IMPLEMENTASI}

\subsection{Kebutuhan sistem}

Dalam perancangan jaringan komputer diskless ada beberapa faktor yang harus diperhatikan yaitu spesifikasi server, thin client dan boot method.

a) Spesifikasi server

- Penggunaan memori pada server mengacu pada formula $256+(192 *$ users $) \mathrm{MB}$, dimana dalam percobaan ini menggunakan 4 buah client, sehingga jumlah memori yang dibutuhkan adalah sebesar $256+(192 * 4)=1024 \mathrm{MB}$

- Processor, seberapa cepat processor yang dibutuhkan tergantung dari aplikasi apa yang akan dipergunakan, dalam percobaan penilitian ini akan digunakan aplikasi seperti openOffice, Gimp dan Firefox. Dan processor yang digunakan adalah Processor Core 2 Duo $2400 \mathrm{MHz}$

b) Spesifikasi thin client

- Pocessor yang digunakan diclient minimal adalah diatas $533 \mathrm{MHz}$

- Memori yang digunakan minimal adalah $48 \mathrm{MB}$

- Video Card yang digunakan minimal $32 \mathrm{MB}$

c) Boot method

Client pada jaringan komputer diskless melakukan proses booting melalui jaringan, menggunakan program yang disebut network boot loader. Dalam percobaan, metode booting yang digunakan adalah menggunakan PXE (Pre-boot Execution Environment). Client yang tidak memiliki lan card on board yang sudah mendukung PXE akan ditambahkan dengan lan card external yang sudah mendukung PXE [1]. Pada penelitian digunakan lan card external menggunakan Realtek RTL8139D.

\subsection{Spesifikasi Perangkat yang Digunakan}

Dalam percobaan ini spesifikasi hardware yang digunakan adalah sebagai berikut :

a) Server

- $\quad$ Processor Core 2 Duo $2400 \mathrm{MHz}$

- $\quad$ Memori DDR 2 1GB

- Hard Disk 20 GB 7200 RPM

- LAN Card 10/100 MBps Realtek

- Switch/Hub $100 \mathrm{MBps}$

- $\quad$ VGA On board $128 \mathrm{MB}$ share memory 
- $\quad$ Sistem Operasi Linux Ubuntu 8.04 ditambah dengan LTSP 5.0

b) Client 1

- $\quad$ Processor AMD $1100 \mathrm{MHz}$

- $\quad$ Memori SDR $128 \mathrm{MB}$

- $\quad$ LAN Card 10/100 MBps Realtek

- VGA On board $32 \mathrm{MB}$ share memory

c) Client 2,3,4 (Tambahan komputer 5,6,7 dan 8)

- $\quad$ Processor Pentium D $1100 \mathrm{MHz}$

- $\quad$ Memori DDR $512 \mathrm{MB}$

- $\quad$ LAN Card 10/100 MBps Realtek

- $\quad$ VGA On board 32 MB share memory

\subsection{Skenario Pengujian}

Dalam pengujian pada ini telah diuji beberapa parameter yaitu :

a) Performasi $C P U$ server ditinjau dari segi $C P U$ utilization

b) Penggunaan memori dengan jumlah delapan client dengan mengacu kepada spesifikasi hardware pada point 3.2, dengan skenario sebagai berikut :

- Thin-Client tidak menjalankan aplikasi apapun

- Thin-Client menjalankan aplikasi Open Office

- Thin-Client menjalankan aplikasi Gimp

- Thin-Client menjalankan aplikasi Firefox

\subsection{Pengujian dan analisa cpu utilization}

Pada pengujian diketahui seberapa besar penggunaan CPU Utilization LTSP server ketika melayani 8 buah client, dimana client menjalankan aplikasi OpenOffice, GIMP dan Firefox. Data yang diperoleh adalah seperti ditunjukkan pada Gambar 1.

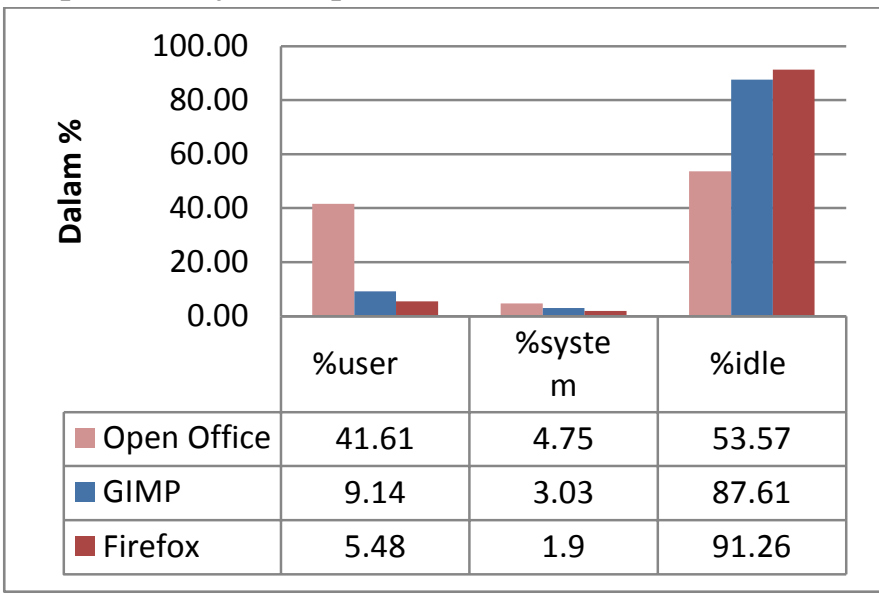

Gambar 1. Grafik CPU utilization 8 client menjalankan aplikasi OpenOffice, GIMP dan Firefox 


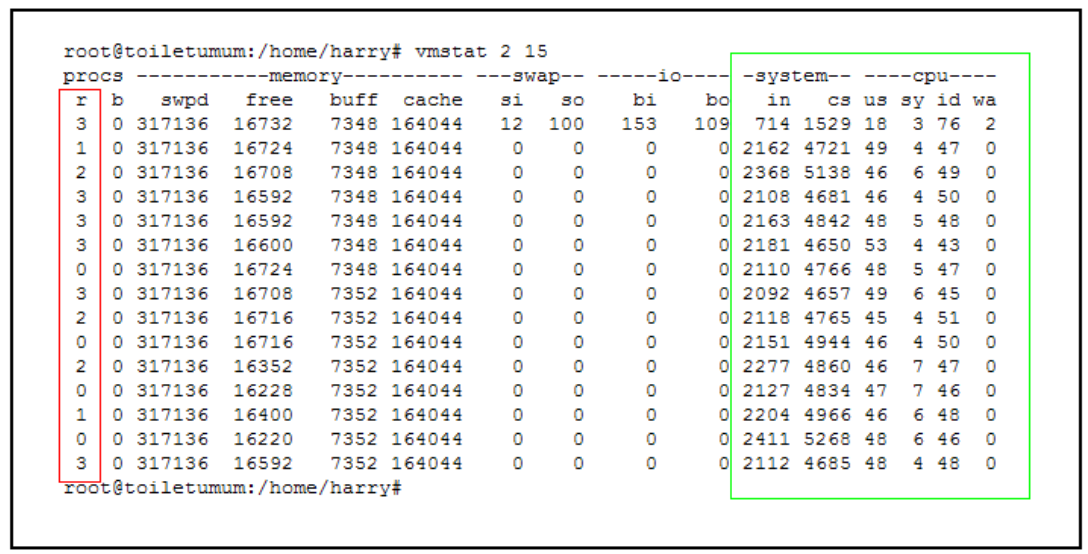

Gambar 2. Sampling CPU utilization server ketika 8 client menjalankan aplikasi OpenOffice

Dari Gambar 1 dan Gambar 2 dapat diketahui bahwa dari ketiga aplikasi yang diuji coba Open Office menduduki penggunaan CPU paling banyak yaitu 41,61\% untuk user, 4,75\%system dan 53,57 \%idle, sedangkan posisi kedua penggunaan CPU paling banyak adalah ketika client menjalankan aplikasi GIMP dengan 9,14 \%user, 3,03 \%system dan 87,61\% idle, dan ketika client menjalankan aplikasi Firefox didapatkan 5,48 \% user, 1,9\%system dan 91,26 \%idle. Semakin besar persentase dari nilai idle menunjukan bahwa CPU tidak terlalu sibuk. Penggunaan CPU dengan ketiga aplikasi tersebut masih dalam keseimbangan yaitu 65-70\% untuk user time, 30-35\% untuk system time dan 0-0,5 \%idle time. Dari sampling data juga didapatkan bahwa nilai antrian (run quеие) tidak melebihi 3 threads perprosesor. Dari data-data tersebut dapat disimpulkan bahwa tidak ada masalah dalam CPU utilization pada server ketika client menjalan kan aplikasi yang diuji.

\subsection{Pengujian dan analisa penggunaan memori LTSP Server}

Dalam pengujian penggunaan memori LTSP Server digunakan perintah "free" untuk pengambilan data. Dimana perintah "free" menampilkan total jumlah memori yang digunakan dan jumlah memori yang tidak digunakan, perintah ini juga menampilkan swap dalam sistem. Pada pengujian ini ingin diketahui seberapa besar penggunaan memori LTSP server ketika melayani 8 buah client. Data yang didapat adalah sebagai berikut:

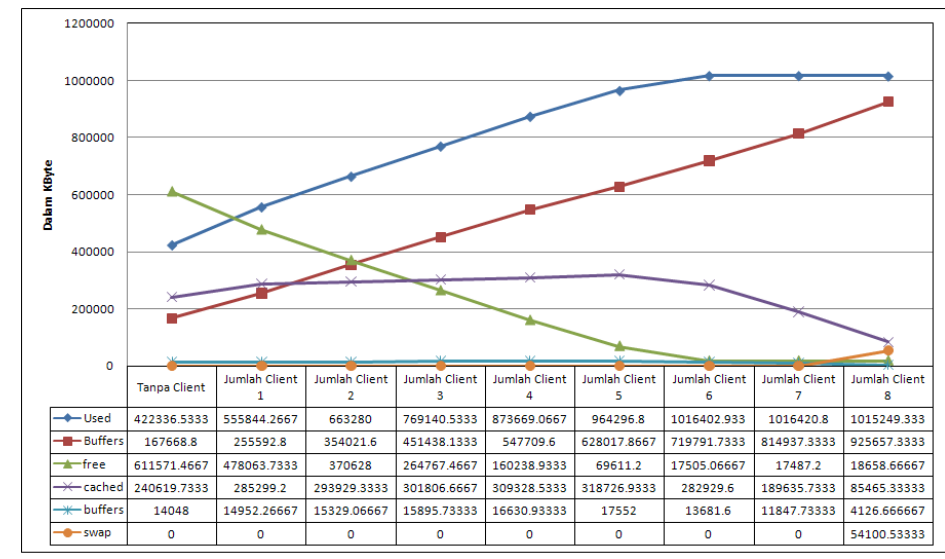

Gambar 3. Grafik Penggunaan memory LTSP server ketika client tidak menjalan kan aplikasi apapun 


\begin{tabular}{|c|c|c|c|c|c|c|c|c|c|c|c|c|c|c|}
\hline \multicolumn{14}{|c|}{ root@toiletumum:/home/harry vmsta } & \\
\hline & swpd & free & buff & cache & $s i$ & so & bi & bo & in & $c s$ & us & sy & & wa \\
\hline 00 & 52068 & 16760 & 4072 & 86152 & 1 & 20 & 373 & 44 & 320 & 880 & 10 & 3 & 83 & 4 \\
\hline 00 & 52068 & 16744 & 4072 & 86152 & 0 & 0 & 0 & 0 & 56 & 599 & 0 & 0 & 100 & 0 \\
\hline 00 & 52068 & 16752 & 4072 & 86152 & 0 & 0 & 0 & 0 & 51 & 570 & 0 & 0 & 100 & 0 \\
\hline 00 & 52068 & 16744 & 4072 & 86152 & 0 & 0 & 0 & 0 & 51 & 590 & 0 & 0 & 100 & 0 \\
\hline $0 \quad 0$ & 52068 & 16752 & 4072 & 86152 & 0 & 0 & 0 & 0 & 55 & 597 & 0 & 0 & 100 & 0 \\
\hline 00 & 52068 & 16744 & 4072 & 86152 & 0 & 0 & 0 & 0 & 48 & 563 & 0 & 0 & 100 & 0 \\
\hline $0 \quad 0$ & 52068 & 16744 & 4072 & 86152 & 0 & 0 & 0 & 0 & 57 & 577 & 0 & 0 & 100 & 0 \\
\hline $0 \quad 0$ & 52068 & 16744 & 4072 & 86152 & 0 & 0 & 0 & 0 & 49 & 568 & 0 & 0 & 100 & 0 \\
\hline $0 \quad 0$ & 52068 & 16744 & 4072 & 86152 & 0 & 0 & 0 & 0 & 53 & 585 & 0 & 0 & 100 & 0 \\
\hline 00 & 52068 & 16752 & 4072 & 86152 & 0 & 0 & 0 & 0 & 60 & 613 & 0 & 0 & 100 & 0 \\
\hline 00 & 52068 & 16752 & 4076 & 86152 & 0 & 0 & 0 & 0 & 53 & 589 & 0 & 0 & 100 & 0 \\
\hline $0 \quad 0$ & 52068 & 16628 & 4076 & 86152 & 0 & 0 & 0 & 0 & 57 & 602 & 0 & 0 & 100 & 0 \\
\hline 00 & 52068 & 16620 & 4076 & 86152 & 0 & 0 & 0 & 0 & 80 & 596 & 0 & 0 & 100 & 0 \\
\hline $0 \quad 0$ & 52068 & 16620 & 4076 & 86152 & 0 & 0 & 0 & 0 & 52 & 595 & 0 & 0 & 100 & 0 \\
\hline $0 \quad 0$ & 52068 & 16628 & 4076 & 86152 & 0 & 0 & 0 & 0 & 51 & 571 & 0 & 0 & 99 & 0 \\
\hline roo & 1etur & . & & & & & & & & & & & & \\
\hline
\end{tabular}

Gambar 4. Sampling penggunaan memori server ketika 8 client tidak menjalankan aplikasi apapun

Dari gambar 3 dapat diketahui bahwa dengan $1 \mathrm{G}$ memori, ternyata server mampu menangani client sebanyak 8 buah. Penggunaan memori (used) terbesar sebanyak 1.016.402,93 Kbyte, penggalokasian swap muncul ketika nilai free memori berkisar dikisaran 17.000 Kbyte pada saat client berjumlah tujuh buah, akan tetapi jika dilihat hasil sampling data pada gambar 4 tidak ada aktifitas So, Si, Bo dan Bi ini menunjukan bahwa swap hanya dialokasikan akan tetapi tidak dipergunakan.

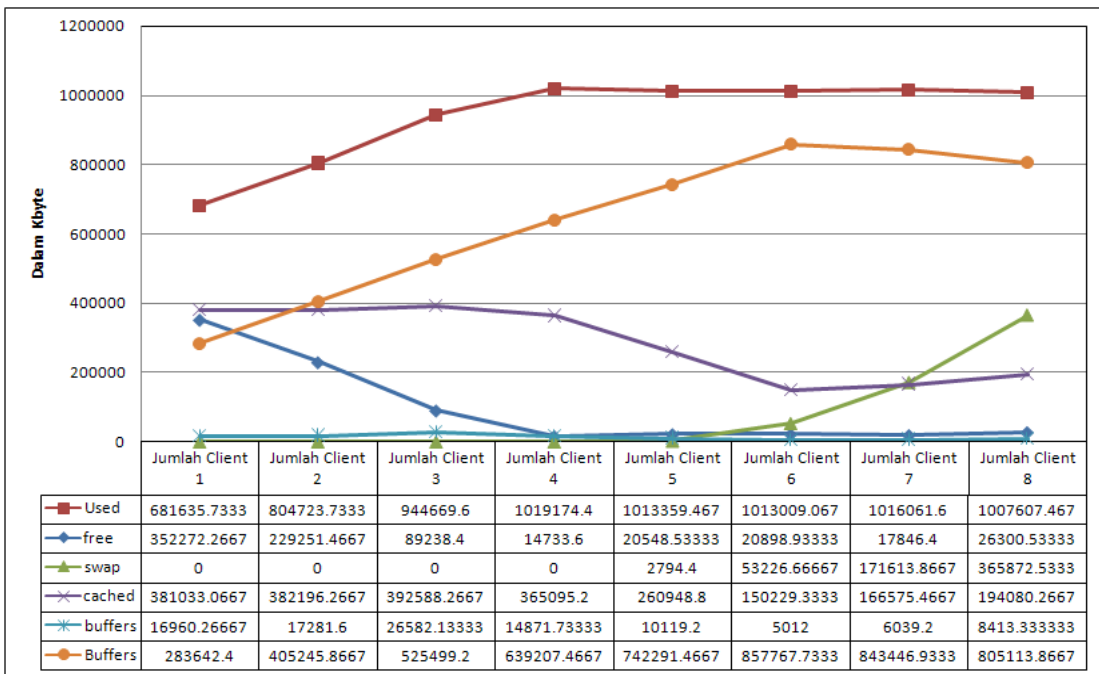

Gambar 5. Grafik Penggunaan memory LTSP server ketika client menjalan kan aplikasi OpenOffice

Dari gambar 5 dapat diketahui bahwa dengan $1 \mathrm{G}$ memori, ternyata server mampu menangani client sebanyak 8 buah, dimana client menjalankan aplikasi OpenOffice. Penggunaan memori (used) terbesar sebanyak 1.019.174,4 Kbyte, penggalokasian swap muncul ketika nilai free memori berkisar 14.000-20.000 Kbyte saat jumlah client berjumlah 5 buah, akan tetapi jika dilihat hasil sampling data pada gambar 6 tidak ada aktifitas So, Si, Bo dan Bi ini menunjukan bahwa swap hanya dialokasikan akan tetapi tidak dipergunakan. Dengan ini dapat disimpulan bahwa tidak ada masalah dengan jumlah memori $1 \mathrm{G}$ pada server, ketika 8 client menjalankan aplikasi OpenOffice. 


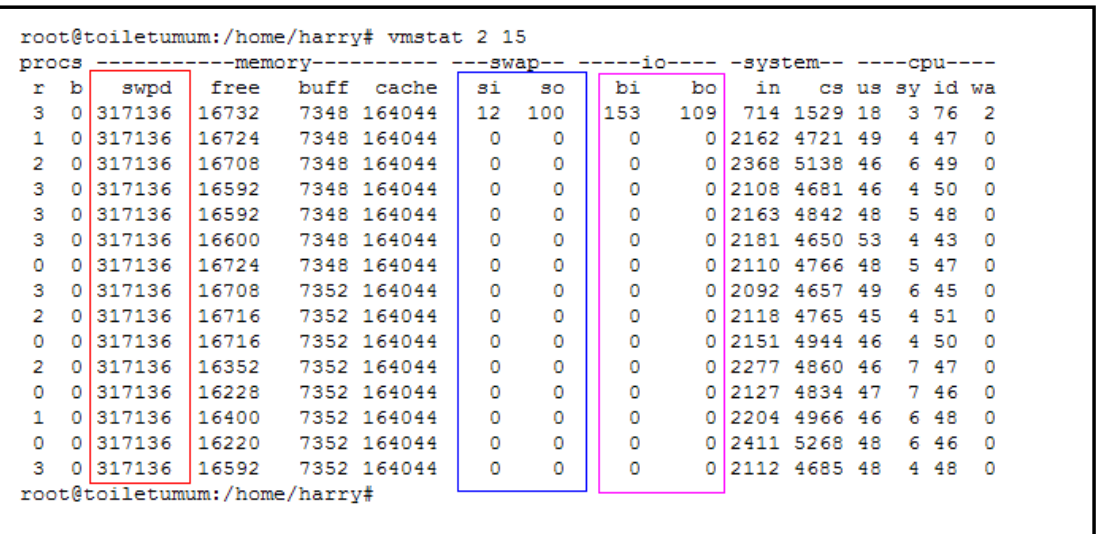

Gambar 6. Sampling penggunaan memori server ketika 8 client menjalankan aplikasi OpenOffice

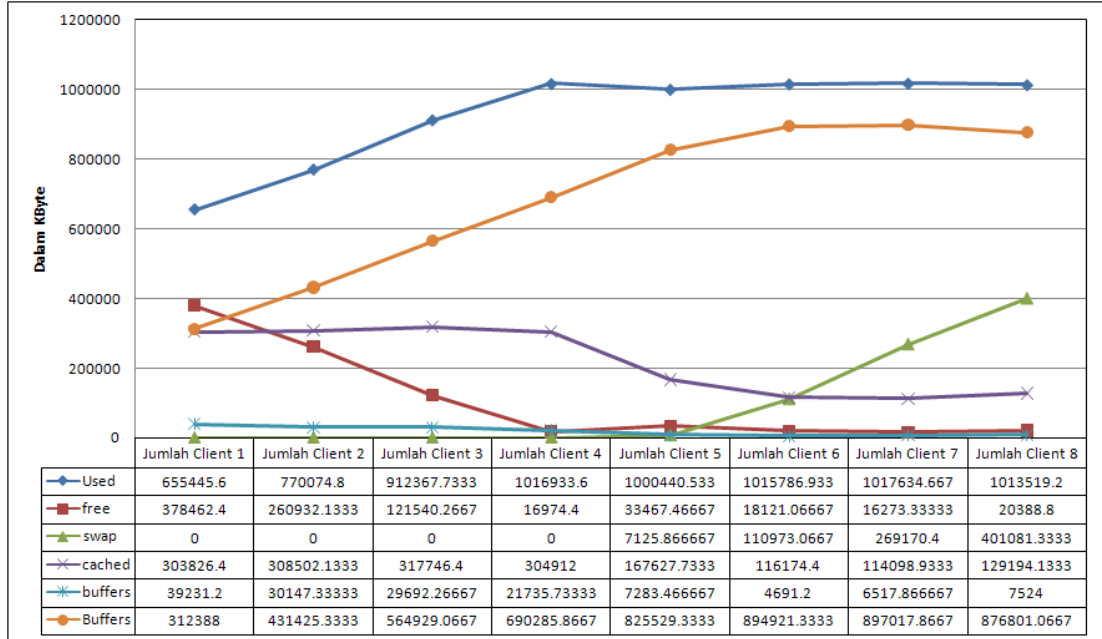

Gambar 7. Grafik Penggunaan memory LTSP server ketika client menjalan kan aplikasi GIMP

\begin{tabular}{|c|c|c|c|c|c|c|c|c|c|c|c|c|c|c|}
\hline \multirow{2}{*}{ procs } & \multirow{2}{*}{ swpd } & \multicolumn{3}{|c|}{---memory---------- } & \multirow{2}{*}{\multicolumn{2}{|c|}{-- swap-- }} & \multicolumn{2}{|c|}{----10--- } & \multicolumn{2}{|c|}{-system-- } & \multicolumn{4}{|c|}{---- сpu---- } \\
\hline & & free & buff & cache & & so & bi & bo & in & $\mathrm{cs}$ & us & $s \mathrm{y}$ & id & wa \\
\hline 0 & 376820 & 15068 & 7232 & 76532 & 33 & 206 & 216 & 218 & 480 & 956 & 8 & 2 & 86 & 3 \\
\hline 0 & 376820 & 15060 & 7232 & 76532 & 0 & 0 & 0 & 0 & 59 & 609 & 0 & 0 & 100 & 0 \\
\hline 0 & 376820 & 15008 & 7232 & 76532 & 0 & 0 & 0 & 0 & 734 & 1464 & 3 & 1 & 96 & 0 \\
\hline 0 & 376820 & 14560 & 7232 & 76532 & 0 & 0 & 0 & 0 & 5517 & 6001 & 22 & 6 & 72 & 0 \\
\hline 1 & 376720 & 14352 & 7232 & 76540 & 36 & 0 & 36 & 0 & 1709 & 2741 & 7 & 3 & 90 & 1 \\
\hline 0 & 376600 & 13448 & 7232 & 76532 & 80 & 0 & 80 & 0 & 5135 & 7121 & 19 & 8 & 73 & 0 \\
\hline 0 & 376560 & 13048 & 7232 & 76532 & 0 & 0 & 0 & 0 & 2580 & 4133 & 9 & 3 & 88 & 0 \\
\hline 0 & 381384 & 15492 & 7232 & 76384 & 0 & 2404 & 0 & 2404 & 2314 & 4860 & 12 & 4 & 83 & 1 \\
\hline 1 & 381384 & 14552 & 7232 & 76384 & 0 & 0 & 0 & 0 & 4449 & 6987 & 20 & 7 & 73 & 0 \\
\hline 0 & 381384 & 13796 & 7232 & 76384 & 0 & 0 & 0 & 0 & 4058 & 8043 & 14 & 8 & 78 & 0 \\
\hline 1 & 381384 & 12936 & 7232 & 76384 & 0 & 0 & 0 & 0 & 5167 & 9154 & 17 & 9 & 74 & 0 \\
\hline 0 & 381464 & 28304 & 7232 & 62632 & 0 & 40 & 0 & 40 & 2714 & 4781 & 10 & 4 & 86 & 0 \\
\hline 2 & 381464 & 27508 & 7232 & 62632 & 16 & 0 & 16 & 0 & 2435 & 2491 & 9 & 3 & 88 & 0 \\
\hline 2 & 381464 & 27040 & 7232 & 62632 & 0 & 0 & 0 & 0 & 6053 & 5112 & 20 & 7 & 73 & 0 \\
\hline 0 & 381464 & 26812 & 7232 & 62632 & 0 & 0 & 0 & 0 & 6109 & 5075 & 19 & 5 & 76 & 0 \\
\hline ma & & $\mathrm{m}: / \mathrm{hom}$ & hrr & & & & & & & & & & & \\
\hline
\end{tabular}

Gambar 8. Sampling penggunaan memory server ketika 8 client menjalankan aplikasi GIMP

Dari gambar 7 dapat diketahui bahwa dengan $1 \mathrm{G}$ memori, ternyata server mampu menangani client sebanyak 8 buah, dimana client menjalankan aplikasi GIMP. Penggunaan memori (used) terbesar sebanyak 1.017.634,67 Kbyte, penggalokasian swap muncul ketika nilai free memori berkisar 16.000-30.000 Kbyte saat jumlah client berjumlah 5 buah, jika dilihat hasil sampling data pada gambar 4.8 terdapat aktifitas $\mathrm{So}, \mathrm{Si}$, Bo dan Bi ini menunjukan bahwa swap tidak hanya dialokasikan akan tetapi juga dipergunakan. Perlu diperhatikan juga nilai dari 
persentase wa $(\% w a)$, nilai ini tidak terlalu besar sehingga penggunaan swap tidak perlu dikhawatirkan. Dari data-data tersebut dapat disimpulan bahwa tidak ada masalah dengan jumlah memori $1 \mathrm{G}$ pada server, ketika 8 client menjalankan aplikasi GIMP.

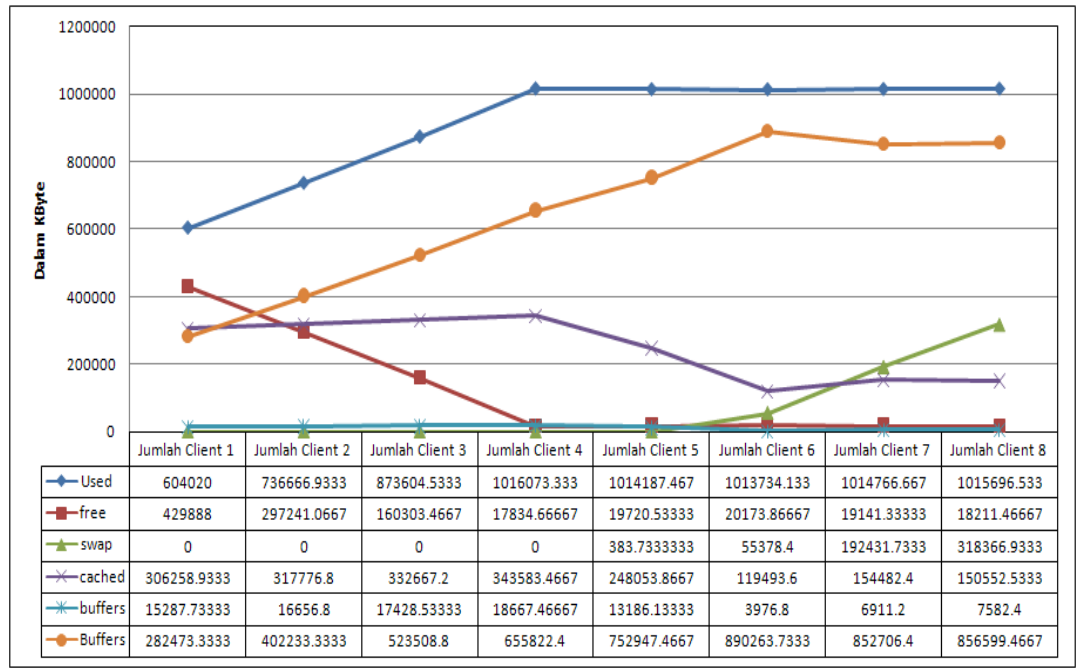

Gambar 9. Grafik penggunaan memori di LTSP Server ketika client menggunakan aplikasi Firefox

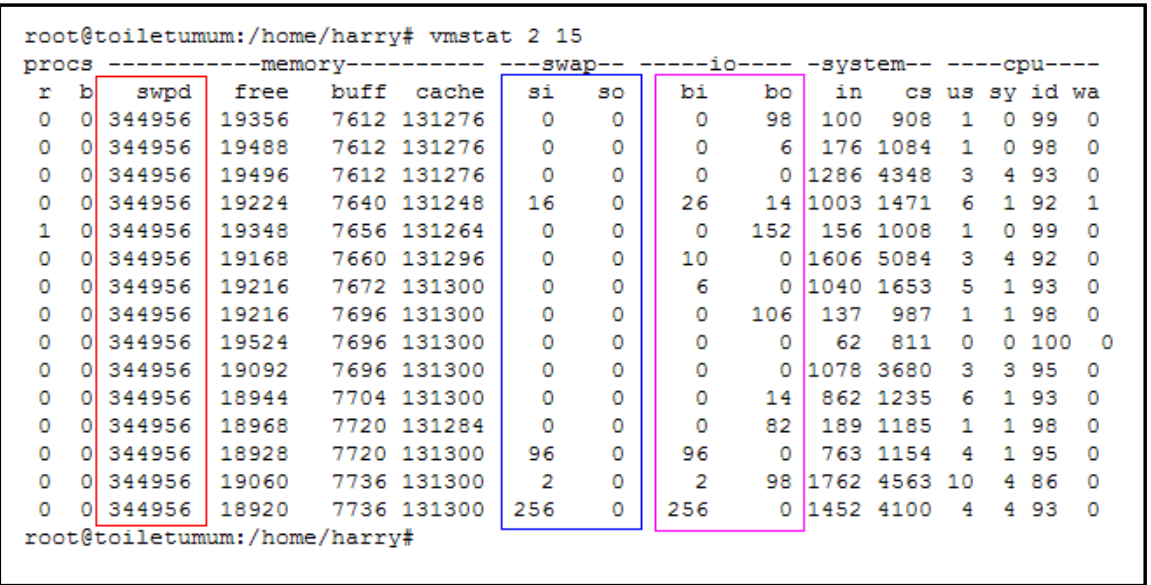

Gambar 10. Sampling penggunaan memory server ketika 8 client menjalankan aplikasi Firefox

Dari gambar 9 dapat diketahui bahwa dengan $1 \mathrm{G}$ memori, ternyata server mampu menangani client sebanyak 8 buah, dimana client menjalankan aplikasi Firefox. Penggunaan memori (used) terbesar sebanyak 1.016.073,33 Kbyte, penggalokasian swap muncul ketika nilai free memori berkisar 17.000 Kbyte -19.000 Kbyte saat jumlah client berjumlah 5 buah, jika dilihat hasil sampling pada gambar 4.10 terdapat aktifitas $\mathrm{So}, \mathrm{Si}$, Bo dan Bi ini menunjukan bahwa swap tidak hanya dialokasikan akan tetapi juga dipergunakan. Perlu diperhatikan juga nilai dari persentase wa $(\% w a)$, nilai ini tidak terlalu besar sehingga penggunaan swap tidak perlu dikhawatirkan. Dari data-data tersebut dapat disimpulan bahwa tidak ada masalah dengan jumlah memori $1 \mathrm{G}$ pada server, ketika 8 client menjalankan aplikasi FireFox.

\section{KESIMPULAN}

Penggunaan CPU LTSP server ketika thin client menjalankan aplikasi OpenOffice, GIMP atau Firefox masih dalam keseimbangan berkisar antara 65-70\% untuk user time, 30-35\% untuk 
system time dan 0-0,5\% idle time yaitu ketika client menjalankan Open Office sebesar 41,61\%, untuk user, 4,75\% system dan 53,57 \%idle, sedangkan posisi kedua penggunaan CPU paling banyak adalah ketika client menjalankan aplikasi GIMP dengan 9,14 \% user, 3,03\%system dan $87,61 \%$ idle, dan ketika client menjalankan aplikasi Firefox didapatkan 5,48\% user, 1,9\% system dan $91,26 \%$ idle. Semakin besar persentase dari nilai idle menunjukan bahwa CPU tidak terlalu sibuk., selain itu didapatkan bahwa nilai antrian (run queue) tidak melebihi 3 threads perprosesor. Hal ini berarti tidak ada masalah dalam CPU utilization pada server ketika client menjalan kan aplikasi yang diuji. Dari sisi penggunaan memori, dengan $1 \mathrm{G}$ memori pada server, ternyata server mampu menangani client sebanyak 8 buah, dimana client menjalankan aplikasi OpenOffice, GIMP atau Firefox. Penggalokasian swap muncul ketika nilai free memori berkisar 14.000-30.000 Kbyte, jika dalam sampling data terdapat aktifitas So, Si, Bo dan Bi ini menunjukan bahwa swap tidak hanya dialokasikan akan tetapi juga dipergunakan. Perlu diperhatikan juga nilai dari persentase wa $(\% w a)$, jika nilai ini tidak terlalu besar maka penggunaan swap tidak perlu dikhawatirkan. Dengan demikan tidak ada masalah dengan jumlah memori $1 \mathrm{G}$ pada server, ketika 8 client menjalankan aplikasi yang diuji.

\section{DAFTAR PUSTAKA}

[1] How PXE Works, URL: http://www.pxe.ca/how.html, (Oktober 2009)

[2] Honch, Darren.2009.Linux System and Performance Monitoring.Penerbit O’Relly.USA

[3] Husni. 2004 .Implementasi Jaringan Komputer dengan Linux Redhat 9. Penerbit Andi. Yogyakarta.

[4] Linux Terminal Server Project, URL : http://www.ltsp.org, (Oktober 2009)

[5] LTSP How To,URL: http//www.ubuntu.com, (Oktober 2009)

[6] Purbo, Onno W. 2006 .PC Cloning Windows pakai Linux LTSP. Penerbit Andi.Yogyakarta.

[7] Van Vogt, Sander.2009. Pro Ubuntu Server Administration. Penerbit Apress.USA 